\title{
Locus coeruleus cellular and molecular pathology during the progression of Alzheimer's disease
}

\author{
Sarah C. Kelly ${ }^{1,2}$, Bin He ${ }^{5}$, Sylvia E. Perez ${ }^{5}$, Stephen D. Ginsberg ${ }^{6,7,8}$, Elliott J. Mufson ${ }^{5}$ and Scott E. Counts ${ }^{1,2,34^{*}}$
}

\begin{abstract}
A major feature of Alzheimer's disease (AD) is the loss of noradrenergic locus coeruleus (LC) projection neurons that mediate attention, memory, and arousal. However, the extent to which the LC projection system degenerates during the initial stages of AD is still under investigation. To address this question, we performed tyrosine hydroxylase (TH) immunohistochemistry and unbiased stereology of noradrenergic LC neurons in tissue harvested postmortem from subjects who died with a clinical diagnosis of no cognitive impairment $(\mathrm{NCl})$, amnestic mild cognitive impairment (aMCl, a putative prodromal AD stage), or mild/moderate AD. Stereologic estimates of total $\mathrm{LC}$ neuron number revealed a 30\% loss during the transition from $\mathrm{NCl}$ to aMCl, with an additional $25 \%$ loss of $L C$ neurons in AD. Decreases in noradrenergic LC neuron number were significantly associated with worsening antemortem global cognitive function as well as poorer performance on neuropsychological tests of episodic memory, semantic memory, working memory, perceptual speed, and visuospatial ability. Reduced LC neuron numbers were also associated with increased postmortem neuropathology. To examine the cellular and molecular pathogenic processes underlying $\mathrm{LC}$ neurodegeneration in aMCl, we performed single population microarray analysis. These studies revealed significant reductions in select functional classes of mRNAs regulating mitochondrial respiration, redox homeostasis, and neuritic structural plasticity in neurons accessed from both $\mathrm{aMCl}$ and $\mathrm{AD}$ subjects compared to $\mathrm{NCl}$. Specific gene expression levels within these functional classes were also associated with global cognitive deterioration and neuropathological burden. Taken together, these observations suggest that noradrenergic LC cellular and molecular pathology is a prominent feature of prodromal disease that contributes to cognitive dysfunction. Moreover, they lend support to a rational basis for targeting LC neuroprotection as a disease modifying strategy.
\end{abstract}

Keywords: Locus coeruleus, Norepinephrine, Mild cognitive impairment, Alzheimer's disease, Neurodegeneration, Gene expression

\section{Introduction}

Sporadic Alzheimer's disease (AD) is believed to have an extensive preclinical stage since neuropathological examinations of older people with a clinical diagnosis of no or mild cognitive impairment (MCI; a putative prodromal stage of $\mathrm{AD}$ ) consistently reveal similar pathological signatures to those with frank $\mathrm{AD}[2,77]$. Thus, identifying events that occur in the preclinical stages of $\mathrm{AD}$ will be

\footnotetext{
* Correspondence: scott.counts@hc.msu.edu

'Department of Translational Science and Molecular Medicine, Michigan

State University, 333 Bostwick Ave NE, Grand Rapids, MI 49503, USA

${ }^{2}$ Cell and Molecular Biology Program, Michigan State University, East Lansing, $\mathrm{MI}$, USA

Full list of author information is available at the end of the article
}

essential for therapeutic target identification within a disease-modifying window. In this regard, noradrenergic neurons of the nucleus locus coeruleus (LC) projection system, which provide the primary source of norepinephrine $(\mathrm{NE})$ to the forebrain, mediate memory and attention $[16,105]$ and degenerate in advanced $\mathrm{AD}[19,24,36,75$, $86,119]$, yet there is evidence for the involvement of this system earlier in the disease process. For instance, neurofibrillary tangle (NFT) deposition in the LC has been noted in aged control and cognitively impaired subjects and LC NFTs correlate with global cognition [55], in line with reduced NE levels in the hippocampus and cortex in $\mathrm{AD}[1,75,94]$. Moreover, it has been suggested that the 
LC is an initial site of NFT formation in young adults and during aging, thus serving as a potential nidus for NFT propagation during disease progression $[21,55]$.

Reductions in LC neuron number are also associated with increased cortical amyloid plaque and NFT loads $[18,108]$ and correlate better with onset and duration of $\mathrm{AD}$ than cholinergic nucleus basalis degeneration [48, 76, 124]. More recently, morphometric studies have shown that 1) the volume and number of total neurons in the LC undergo a step-wise reduction with successive Braak stage [110], and 2) there is a significant loss of neuromelanin-containing LC neurons in individuals meeting the clinical pathologic criteria for MCI [e.g., clinical dementia rating $(C D R)=0.5$ with low to intermediate AD pathology] [7]. In the present study, we expanded on these observations by using tyrosine hydroxylase $(\mathrm{TH})$ immunohistochemistry and unbiased stereology to investigate the extent of noradrenergic LC neuron loss in postmortem samples obtained from subjects who received an antemortem clinical diagnosis of no cognitive impairment (NCI), amnestic MCI (aMCI; the MCI subtype most likely to convert to frank $\mathrm{AD}[96,121,122])$, or mild/moderate AD. THimmunoreactive (-ir) LC neuron numbers were evaluated with respect to both antemortem neuropsychological test scores and postmortem pathological diagnostic criteria.

While morphometric studies of LC cell loss help to delineate its relative status within the spatiotemporal pattern of selective neuronal vulnerability in $\mathrm{AD}[7,108$, 124 , the molecular mechanisms underlying LC neurodegeneration during disease progression have yet to be fully understood. To gain a better understanding of potential molecular mechanisms driving LC neuronal dysfunction during the onset of $\mathrm{AD}$, we combined single neuron RNA amplification strategies with customdesigned microarrays to analyze differential gene expression patterns of individual TH-ir LC neurons accrued from the same NCI, aMCI, and AD cases.

\section{Materials and methods}

\section{Subjects and clinical neuropathologic assessments}

Brainstems from de-identified subjects who died with an antemortem clinical diagnosis of NCI $(n=11)$, aMCI $(n=$ $10)$ or mild/moderate $\mathrm{AD}(n=8)$ representing both genders were obtained from participants in the Rush Religious Orders Study (RROS), a longitudinal clinical pathologic study of aging and $\mathrm{AD}$ in elderly Catholic clergy [14, 87]. The study was determined to be exempt from IRB review by the participating institutions. Although RROS participants are not representative of a community-based sample, the basic neurobiological process underlying cognitive impairment in this cohort is likely the same as in others. For instance, neuropathological studies of MCI show similar results in the RROS [13, 67, 88], Washington University [100], and University of Kentucky [77] cohorts.

Table 1 summarizes the demographic, clinical, and neuropathological characteristics of the subjects examined. Details of cognitive evaluations and diagnostic criteria have been extensively published [14, 34, 87, 95]. Briefly, a team of investigators performed annual neuropsychological performance testing including the Mini Mental State Exam (MMSE) and 17 additional neuropsychological tests referable to five cognitive domains: episodic memory (immediate and delayed recall of the East Boston Story and Story A from Logical Memory, Word List Memory, Word List Recall, Word List Recognition), semantic memory (15-item Boston Naming Test, Verbal Fluency, 15-item word reading test), working memory (Digit Span Forward, Digit Span Backward, Digit Ordering), perceptual speed (Symbol Digit Modalities, Number Comparison), and visuospatial abililty (Judgment of Line Orientation, Standard Progressive Matrices). A Global Cognitive Score (GCS), consisting of a composite $z$-score calculated from this test battery, was determined for each participant. A board-certified neurologist with expertise in the evaluation of the elderly made the clinical diagnosis based on impairments in each of the five cognitive domains and a clinical examination. The diagnosis of dementia or $\mathrm{AD}$ met recommendations by the joint working group of the National Institute of Neurologic and Communicative Disorders and Stroke/AD and Related Disorders Association (NINCDS/ADRDA) [79]. The aMCI subjects exhibited impairment in episodic memory on neuropsychological testing but did not meet the criteria for AD or dementia. These criteria for aMCI are consistent with those used by others in the field [97].

At autopsy, tissue from one hemisphere and brainstem was immersion-fixed in a solution consisting of $4 \%$ paraformaldehyde in 0.1 M phosphate buffer ( $\mathrm{pH} 7.2$ ) for 24-72 h at $4{ }^{\circ} \mathrm{C}$ followed by cryoprotection, whereas tissue from the opposite hemisphere was frozen at $-80{ }^{\circ} \mathrm{C}[34,53,88]$. Series of fixed paraffin embedded tissue were prepared for neuropathological evaluation including visualization and quantitation of neocortical and hippocampal amyloid plaques and NFTs using antibodies directed against $A \beta$ peptide (A $\beta$; 4G8, Covance), tau (PHF1, a gift from Dr. Peter Davies, Hofstra Northwell School of Medicine) [14, 88], as well as thioflavine-S histochemistry and a modified Bielschowsky silver stain. Lewy bodies were revealed using antibodies directed against ubiquitin and $\alpha$-synuclein. Exclusion criteria for cases selected for this study included evidence of argyrophilic grain disease, frontotemporal dementia, Lewy body disease, mixed dementia, Parkinson's disease, and stroke. A board certified neuropathologist blinded to the clinical diagnosis performed the neuropathological evaluation. Neuropathological criteria were based on NIA-Reagan, CERAD, and 
Table 1 Clinical, demographic, and neuropathological characteristics by diagnosis category

\begin{tabular}{|c|c|c|c|c|c|}
\hline & \multicolumn{3}{|c|}{ Clinical Diagnosis } & \multirow[b]{2}{*}{ P-value } & \multirow[b]{2}{*}{ Pair-wise comparison } \\
\hline & $\begin{array}{l}\mathrm{NCl} \\
(N=11)\end{array}$ & $\begin{array}{l}\mathrm{aMCl} \\
(N=10)\end{array}$ & $\begin{array}{l}\mathrm{AD} \\
(N=8)\end{array}$ & & \\
\hline \multicolumn{6}{|l|}{ Age (years) at death: } \\
\hline Mean \pm SD & $82.3 \pm 2.9$ & $85.4 \pm 7.2$ & $84.8 \pm 2.6$ & $0.3^{\mathrm{a}}$ & - \\
\hline (Range) & $(77-86)$ & $(74-96)$ & $(80-88)$ & & \\
\hline Number (\%) of males: & $6(54 \%)$ & $4(40 \%)$ & $4(50 \%)$ & $0.5^{\mathrm{b}}$ & - \\
\hline \multicolumn{6}{|l|}{ Years of education: } \\
\hline Mean \pm SD & $19.1 \pm 2.1$ & $17.9 \pm 5.2$ & $19.0 \pm 2.7$ & $0.9^{\mathrm{a}}$ & - \\
\hline (Range) & $(15-22)$ & $(8-23)$ & $(14-22)$ & & \\
\hline Number (\%) with ApoE $\varepsilon 4$ allele: & $3(27 \%)$ & $2(20 \%)$ & $3(38 \%)$ & $0.2^{\mathrm{b}}$ & - \\
\hline \multicolumn{6}{|l|}{ MMSE: } \\
\hline Mean \pm SD & $27.9 \pm 1.5$ & $26.3 \pm 2.3$ & $20.0 \pm 4.9$ & $0.0008^{a}$ & $\mathrm{NCl}>\mathrm{AD}$ \\
\hline (Range) & $(26-30)$ & $(22-30)$ & $(14-27)$ & & \\
\hline \multicolumn{6}{|l|}{ Global Cognitive Score: } \\
\hline Mean \pm SD & $0.59 \pm 0.3$ & $0.02 \pm 0.3$ & $-1.0 \pm 0.6$ & $0.0002^{\mathrm{a}}$ & $\mathrm{NCl}>(\mathrm{MCl}, \mathrm{AD})$ \\
\hline (Range) & $(-0.08-0.9)$ & $(-0.53-0.3)$ & $(-1.5--0.2)$ & & \\
\hline \multicolumn{6}{|l|}{ Post-mortem interval (hours): } \\
\hline Mean \pm SD & $4.9 \pm 2.0$ & $6.2 \pm 5.2$ & $4.0 \pm 1.1$ & $0.8^{\mathrm{a}}$ & - \\
\hline (Range) & $(2.2-8.5)$ & $(2.0-15.0)$ & $(2.7-5.8)$ & & \\
\hline \multicolumn{6}{|l|}{ Distribution of Braak scores: } \\
\hline 0 & 0 & 0 & 0 & & \\
\hline$|/| \mid$ & 4 & 1 & 0 & $0.02^{\mathrm{a}}$ & $\mathrm{NCl}<\mathrm{AD}$ \\
\hline III/IV & 6 & 7 & 3 & & \\
\hline $\mathrm{V} / \mathrm{VI}$ & 1 & 2 & 5 & & \\
\hline \multicolumn{6}{|c|}{ NIA Reagan diagnosis (likelihood of AD): } \\
\hline No $A D$ & 0 & 0 & 0 & & \\
\hline Low & 5 & 4 & 0 & $0.03^{\mathrm{a}}$ & $(\mathrm{NCl}, \mathrm{MCl})<\mathrm{AD}$ \\
\hline Intermediate & 5 & 4 & 4 & & \\
\hline High & 1 & 2 & 4 & & \\
\hline \multicolumn{6}{|l|}{ CERAD diagnosis: } \\
\hline No $A D$ & 3 & 4 & 0 & & \\
\hline Possible & 2 & 2 & 0 & $0.02^{\mathrm{a}}$ & $(\mathrm{NCl}, \mathrm{MCl})<\mathrm{AD}$ \\
\hline Probable & 4 & 2 & 3 & & \\
\hline Definite & 2 & 2 & 5 & & \\
\hline
\end{tabular}

${ }^{\mathrm{a}}$ Kruskal-Wallis test, with Bonferroni correction for multiple comparisons. ${ }^{\mathrm{b}}$ Fisher's exact test, with Bonferroni correction for multiple comparisons

Braak staging [20, 61, 82]. Amyloid burden and apolipoprotein E (ApoE) genotype were determined for each case as described previously [14, 88].

\section{Immunohistochemistry}

Fixed brainstem samples containing the dorsal pons were cut at $40 \mu \mathrm{m}$-thickness on a freezing, sliding microtome into 18 adjacent series and stored in a cryoprotectant solution until processed. Sections containing the LC were immunostained for $\mathrm{TH}$ to visualize noradrenergic neurons $[35,65]$. A full 1:18 series of sections was blocked in TBS/
$0.25 \%$ Triton X-100/10\% goat serum and incubated overnight with rabbit TH antiserum (1:500; Millipore, Billerica, MA). The sections were then sequentially incubated with biotinylated goat anti-rabbit IgG and avidin-biotin complex (ABC; Vector Labs, Burlingame, $C A$ ) and developed using 3,3'-diaminobenzidine (DAB) enhanced with nickel II sulfate to yield a blue-black reaction product (Fig. 1).

\section{Stereological analysis of LC number}

The optical disector method was used to determine the number of TH-ir neurons in the left hemisphere of the 
A

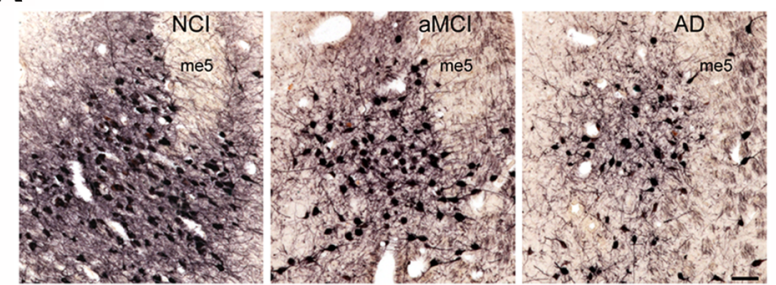

B

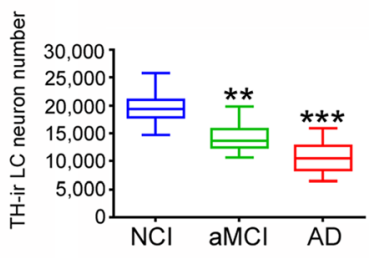

Fig. $1 \mathrm{LC}$ cell loss in aMCl. a Representative TH-ir neuron and fiber staining in dorsal pontine tissue harvested from $\mathrm{NCl}$, aMCl, and mild/moderate AD subjects. $\mathbf{b}$ Unbiased stereological cell counts revealed a significant $\sim 30 \%$ decrease in the number of LC neurons in aMCl compared to $\mathrm{NCI}$ cases. There was a $\sim 50 \%$ loss of LC neurons in the AD group compared to $\mathrm{NCl} .{ }^{* *}, p<0.01,{ }^{* *}, p<0.001$ compared to $\mathrm{NCl}$, via one-way ANOVA with Bonferroni post hoc testing. There was also a significant $\sim 25 \%$ difference in neuronal cell counts between the aMCI and $\mathrm{AD}$ groups $(p<0.05)$. me5 = mesencephalic tract of 5. Scale Bar $=100 \mu \mathrm{m}$

LC (StereoInvestigator, MicroBrightField; Williston, VT) using an Olympus BX-60 microscope coupled to a Prior H128 computer-controlled $x-y-z$ motorized stage and a high-sensitivity Hitachi 3CCD video camera system [90, 91]. Previous studies have demonstrated equivalent neuron numbers between the left and right hemispheres of the LC $[25,50,93]$. The region containing the LC and subcoeruleus was outlined at $5 \mathrm{x}$ and disectors were placed at $1000 \mu \mathrm{m}$ steps along the $x$ - and $y$-axis from a random start within this reference space. The sampling strategy was optimized using the StereoInvestigator oversample-resample probe, such that $\mathrm{TH}$-ir neurons were counted under a $60 \mathrm{x}$ planar oil-immersion objective (1.4 numerical aperture) in a $120 \mu^{2}$ counting frame with a $10 \mu \mathrm{m}$ dissector height. Once the top of the section was in focus, the $z$-plane was lowered 1$2 \mu \mathrm{m}$. Care was taken to ensure that the top forbidden plane was never included in the analysis. Using these parameters, at least $200 \mathrm{TH}$-ir neurons were sampled from each series, achieving coefficients of error [56] values of $<0.10$ [118]. In the present study, lightly and darkly stained $\mathrm{TH}$-ir neurons containing either a well-defined nucleus or nucleolus were counted by a stereologist blinded to the age, sex, cause of death, and clinical classification. Antibody penetration analysis through the full depth of the section was performed to ensure that all objects were counted.

\section{LC neuronal accession and gene expression profiling}

TH-labeled tissue sections processed for customdesigned microarray analysis were prepared without cover-slipping and maintained in RNase-free conditions as described previously for cholinergic nucleus basalis neurons and CA1 pyramidal neurons [27, 53, 54, 111]. Approximately $50 \mathrm{TH}$-ir LC neurons were captured per sample and a total of 3-4 samples of LC neurons/case were accessed by laser capture microdissection (LCM; ArcturusXT; Applied Biosystems, Foster City, CA) and subjected to custom-designed microarray analysis (5150 total neurons, 103 arrays total) [27, 53, 54, 111].
RNA amplification from LC neurons was performed using terminal continuation (TC) RNA amplification $[3,26,52]$. Briefly, microaspirated LC neurons were homogenized in $500 \mu \mathrm{L}$ Trizol reagent (Invitrogen, Carlsbad, CA). RNAs were reverse transcribed in the presence of the poly $\mathrm{d}(\mathrm{T})$ primer $(100 \mathrm{ng} / \mu \mathrm{l})$ and $\mathrm{TC}$ primer $(100 \mathrm{ng} / \mu \mathrm{l})$ in $1 \mathrm{x}$ first strand buffer (Life Technologies, Carlsbad, CA), $2 \mu \mathrm{g}$ of linear acrylamide (Applied Biosystems), $10 \mathrm{mM}$ dNTPs, $100 \mu \mathrm{M}$ DTT, $20 \mathrm{U}$ of SuperRNase Inhibitor (Life Technologies), and 200 $\mathrm{U}$ of reverse transcriptase (Superscript III, Life Technologies). Single-stranded cDNAs were digested with RNase $\mathrm{H}$ and re-annealed with the primers in a thermal cycler: RNase $\mathrm{H}$ digestion step at $37{ }^{\circ} \mathrm{C}, 30 \mathrm{~min}$; denaturation step $95{ }^{\circ} \mathrm{C}, 3 \mathrm{~min}$; primer re-annealing step $60{ }^{\circ} \mathrm{C}, 5 \mathrm{~min}$. This step generated cDNAs with double-stranded regions at the primer interface. Samples were purified by column filtration (Montage PCR filters; Millipore). Hybridization probes were synthesized by in vitro transcription using ${ }^{33} \mathrm{P}$ incorporation in $40 \mathrm{mM}$ Tris (pH 7.5), $6 \mathrm{mM} \mathrm{MgCl} 2,10 \mathrm{mM} \mathrm{NaCl}$, $2 \mathrm{mM}$ spermidine, $10 \mathrm{mM}$ DTT, $2.5 \mathrm{mM}$ ATP, GTP and CTP, $100 \mu \mathrm{M}$ of cold UTP, $20 \mathrm{U}$ of SuperRNase Inhibitor, $2 \mathrm{KU}$ of T7 RNA polymerase (Epicentre, Madison, WI), and $120 \mu \mathrm{Ci}$ of ${ }^{33} \mathrm{P}$-UTP (PerkinElmer, Boston, MA) $[3,27,53]$ at $37{ }^{\circ} \mathrm{C}$ for $4 \mathrm{~h}$. Radiolabeled TC RNA probes were hybridized to customdesigned microarrays without further purification. Arrays were hybridized overnight at $42{ }^{\circ} \mathrm{C}$ in a rotisserie oven and washed sequentially in $2 \mathrm{X} \mathrm{SSC/}$ $0.1 \%$ SDS, $1 \mathrm{X}$ SSC/0.1\% SDS, and $0.5 \mathrm{X}$ SSC/0.1\% SDS for $20 \mathrm{~min}$ each at $42{ }^{\circ} \mathrm{C}$. The arrays were placed in a phosphor screen for $24 \mathrm{~h}$ and developed on a Storm phosphor imager (GE Healthcare, Piscataway, NJ).

\section{Custom-designed microarray platforms and data collection}

Array platforms consisted of $1 \mu \mathrm{g}$ linearized cDNA purified from plasmid preparations adhered to high-density 
nitrocellulose (Hybond WL, GE Healthcare) [3, 26, 52]. The array platform consisted of approximately 576 cDNAs selected to provide a broad spectrum of markers related to pathways of interest in neurobiology (see [111] for a list of array targets). Hybridization signal intensity was determined using Image Quant software (GE Healthcare) and quantified by subtracting background using an empty vector (pBluescript). Expression of TC amplified RNA bound to each linearized cDNA minus background was expressed as a ratio of the total hybridization signal intensity of the array (i.e., global normalization) $[27,52]$. The data analysis generated expression profiles of relative changes in mRNA levels among the noradrenergic LC neurons dissected from each case within the clinical diagnostic groups.

\section{Data analysis and statistics}

Demographic variables (Table 1) were compared among clinical diagnostic groups by Kruskal-Wallis or Fisher's Exact tests with Bonferroni correction for pairwise comparisons. LC neuron number was compared across groups by one-way ANOVA with Bonferroni post hoc testing. Associations between LC neuron number and clinical pathological variables were tested using Spearman rank correlations. Relationships found to be significant by correlation were investigated further using linear regression analysis. The level of statistical significance was set at $p<0.05$.

A one-way ANOVA with post hoc Newman-Keuls analysis was used to evaluate relative changes in total hybridization signal intensity for individual mRNAs. The level of statistical significance was set at $p<0.01$. A false discovery rate controlling procedure was used to reduce type I errors due to the large number of genes analyzed simultaneously [4, 26, 31, 103]. Expression levels of select mRNAs were clustered and displayed using a bioinformatics and graphics software package (GeneLinker Gold, Improved Outcomes, Kingston, ON). Associations between the expression levels of select transcripts and clinical pathological variables were tested using Spearman rank correlations. The level of statistical significance was set at $p<0.05$.

\section{Results}

\section{Case demographics}

Table 1 summarizes the clinical, neuropathological, and demographic characteristics of the 29 cases examined. Statistical analysis revealed no significant differences in age, gender, education level, ApoE4 status, or postmortem interval (PMI) across the groups examined. Cognitive testing scores were available within the last year of life. The average interval from last evaluation to time of death was $7.2 \pm 2.8$ months with no significant differences among the 3 diagnostic groups $(p=0.63)$. The AD subjects performed significantly worse on the MMSE compared to the NCI cases $(p=0.0008)$, and GCS $z$ scores were significantly decreased in aMCI and $\mathrm{AD}$ compared to NCI $(p=0.0002)$. Braak scores were also significantly different across the clinical groups. The NCI cases displayed significantly lower Braak scores than the $\mathrm{AD}$ group $(p=0.02)$. NCI cases were classified as Braak stages I/II (36\%), III/IV (54\%), or V/VI (10\%). The aMCI cases met the criteria for Braak stages I/II (10\%), III/IV (70\%), and V/VI (20\%), and the AD cohort was classified as either Braak stages III/IV (38\%) or V/VI (62\%). The NIA-Reagan diagnosis for likelihood of AD significantly differentiated $\mathrm{NCI}$ and aMCI from AD subjects $(p=0.03)$. CERAD scores were significantly higher in $\mathrm{AD}$ compared to $\mathrm{NCI}$ and $\mathrm{aMCI}(p=0.02)$.

\section{LC neuronal cell loss during the progression of $A D$}

$\mathrm{TH}$ immunohistochemistry was used to estimate changes in the number of noradrenergic LC neurons across the clinical diagnostic groups (Fig. 1). Qualitatively, we observed a step-wise decrement in TH-ir neurons within the $\mathrm{LC}$ from $\mathrm{NCI}$ to aMCI to mild/moderate AD (Fig. 1a). Unbiased stereological cell counts validated these observations. The estimated number of TH-ir LC neurons in the NCI group was $19,495 \pm 2,891$ (mean \pm $\mathrm{SD}$; range $=25,867-14,758$ ), whereas neuron number was progressively decreased in the aMCI $(14,283 \pm 2,757$; range $=19,874-10,645)$ and $\mathrm{AD}(10,628 \pm 2,946$; range $=15,834-6,453)$ groups. Statistical comparisons revealed a significant $\sim 30 \%$ decrease in the number of LC neurons in aMCI compared to NCI cases $(p<0.01)$ (Fig. 1b). An additional $\sim 25 \%$ decrease in LC neuron number was quantified in $\mathrm{AD}$ compared to aMCI $(p<0.05)$, resulting in a $\sim 45-50 \%$ loss of LC neurons in the AD group compared to NCI $(p<0.001)$ (Fig. 1b). Total LC neuron number was similar between males and females in each diagnostic group (data not shown).

\section{Clinical pathologic correlations}

Estimated TH-ir LC neuronal counts were correlated with demographic data, antemortem cognitive test performance, and postmortem neuropathologic variables. Neuron number was not associated with age $(r=-0.18$, $p=0.3)$ or PMI $(r=0.07, p=0.5)$. There were no associations between neuron number and gender or ApoE status (data not shown). However, there was a strong association between reduction in LC neuron number and decline in cognitive status. For instance, lower LC neuron numbers and MMSE scores displayed a significant positive association $(r=0.61, p<0.001)$. Moreover, TH-ir LC neuron number was significantly associated with individual GCS, the composite $z$-score of the 17 neuropsychological tests administered prior to death $(r$ $=0.7, p<0.0001$ ) (Fig. 2), as well as with the final 
A

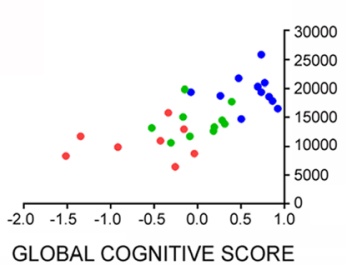

D

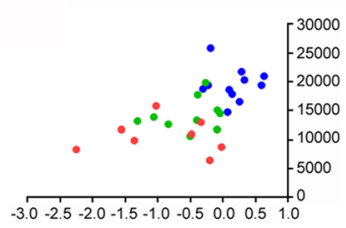

WORKING MEMORY SCORE

G

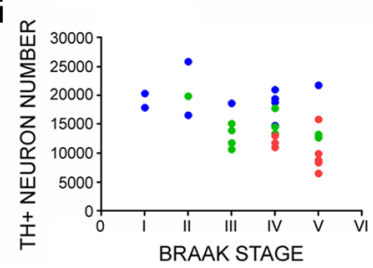

B
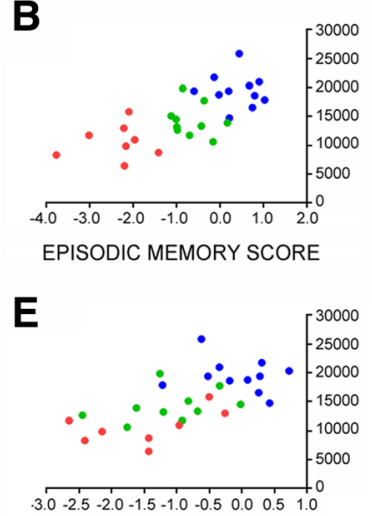

PERCEPTUAL SPEED SCORE

\section{H}

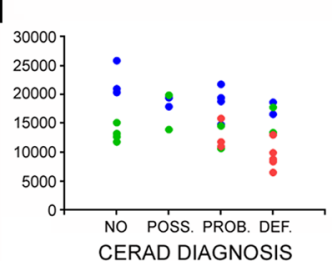

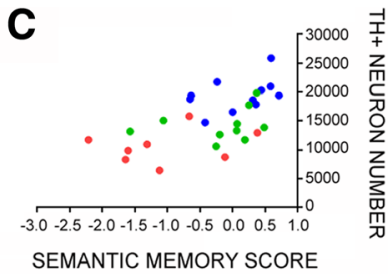

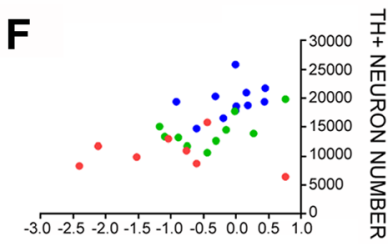

VISUOSPATIAL ABILITY SCORE

I

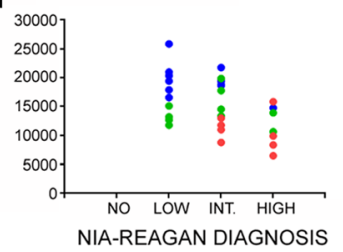

Fig. 2 TH-ir LC neuron number correlates with multiple measures of antemortem cognition and postmortem neuropathology during the progression of AD. Scatterplots show significant relationships between reductions in LC neurons and $\mathbf{a}$ the GCS for each individual $(r=0.7, p<$ 0.0001), as well as poorer performance on composite scores of $\mathbf{b}$ episodic memory $(r=0.71, p<0.0001)$, c semantic memory $(r=0.598, p=$ 0.0008), d working memory ( $r=0.6, p=0.0006)$, e perceptual speed $(r=0.66, p<0.0001)$, and $\mathbf{f}$ visuospatial ability $(r=0.53, p=0.003)$. There were also significant negative correlations between $\mathrm{TH}+$ neuron number and increasing neuropathology as defined by $\mathbf{g}$ Braak $(r=-0.46, p=0.01), \mathbf{h}$ $\operatorname{CERAD}(r=-0.41, p=0.03)$, and $\mathbf{i}$ NIA-Reagan $(r=-0.45, p=0.01)$ diagnostic criteria. All associations were tested using Spearman rank correlation analysis. Abbreviations: TH+ (TH-positive), POSS. (possible), PROB. (probable), DEF. (definite), INT. (intermediate). Symbols: $\mathrm{NCl}$ (blue-filled circle), aMCI (green-filled circle), AD (red-filled circle)

composite scores referable to episodic memory $(r=0.71$, $p<0.0001)$, sematic memory $(r=0.58, p=0.0008)$, working memory $(r=0.6, p=0.0006)$, perceptual speed $(r=$ $0.66, p<0.0001)$, and visuospatial ability $(r=0.53, p=$ 0.003; Fig. 2) [14]. Notably, most of these positive associations between LC neuron numbers and cognitive test scores remained significant even when the NCI and aMCI groups alone were analyzed (Table 2). With respect to neuropathological diagnostic criteria, reductions in TH-ir LC neuron numbers were negatively correlated with increasing measures of neuropathology as characterized by Braak $(r=-0.46, p=0.01)$, NIA-Reagan $(r=$ $-0.45, p=0.01)$, and CERAD $(r=-0.41, p=0.03)$ staging (Fig. 2). Finally, regression modeling revealed that only GCS $(p=0.004)$, but not Braak $(p=0.49)$, NIA-Reagan $(p=0.81)$, or CERAD $(p=0.28)$ score, served as a predictor for the number of TH-ir LC neurons.

\section{Dysregulation of $\mathrm{LC}$ neuronal gene expression in $\mathrm{MCl}$ and} AD

To identify potential molecular pathogenic alterations underlying LC cell loss observed during AD progression, we performed custom-designed microarray analysis using mRNA extracted from individual TH-ir LC neurons accessed from the NCI, aMCI and mild/moderate AD cases. LC neurons displayed a significant downregulation of transcripts regulating mitochondrial function in aMCI and AD compared to NCI subjects (Fig. 3a, b). Significant downregulation was observed for select genes regulating respiration, including cytochrome $\mathrm{C} 1$ (Cytc1; 50\%; $p<$ $0.01)$ and nuclear respiratory factor $1(N r f 1 ; 45 \% ; p<0.01)$, as well as redox gene expression, including superoxide dismutase 2 (Sod2; 50\%; $p<0.01)$ and glutathione peroxidase 1 (Gpx1; 55\%; $p<0.001)$. By contrast, significant upregulation in the expression of the phosphofructokinaseliver $(P f k l ; 50 \% ; p<0.01)$ and phosphofructokinase-platelet $(P f k p ; 50 \% ; p<0.01)$ isozymes were detected in LC

Table 2 Correlations between neuron number and cognitive test scores: $\mathrm{NCl}$ and aMCl subjects only

\begin{tabular}{ll}
\hline MMSE & $r=0.46(p=0.03)$ \\
GCS & $r=0.58(p=0.006)$ \\
episodic memory & $r=0.55(p=0.01)$ \\
semantic memory & $r=0.29(p=0.2)$ \\
working memory & $r=0.6(p=0.004)$ \\
perceptual speed & $r=0.51(p=0.02)$ \\
visuospatial ability & $r=0.55(p=0.009)$ \\
\hline
\end{tabular}




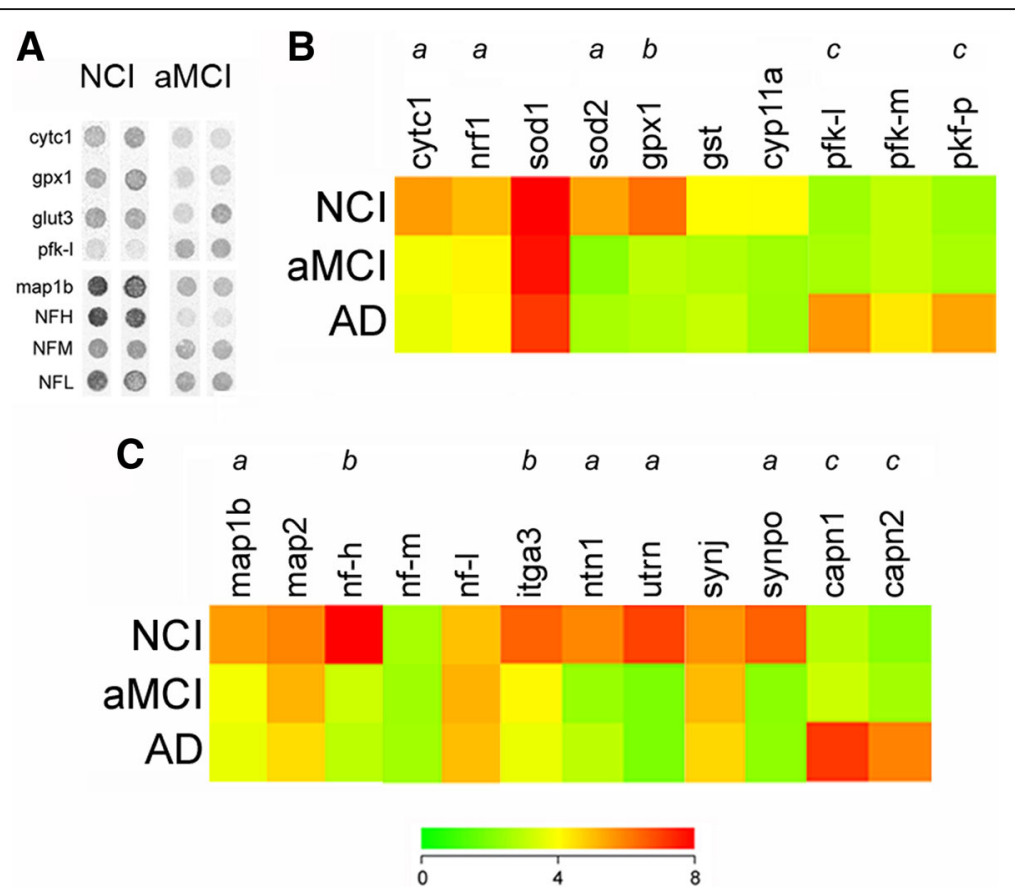

Fig. 3 Single LC neuron expression profiling reveals alterations in mRNAs regulating mitochondrial and neuritic function during AD progression. a Primary custom microarray data showing hybridization signal intensities of select mRNA transcripts within TH-ir LC neurons in NCI and aMCl. Abbreviations: cytochrome C1 (Cytc1), glutathione peroxidase (Gpx1), glucose transporter 3 (Glut3), phosphofructokinase-liver isozyme (Pfkl), microtubule associated binding protein 1a (Mapla), and neurofilament heavy (Nfh), medium (Nfm), or light (Nff) chain subunits. b Heatmap shows significant decreases in transcripts regulating mitochondrial fucntion in LC neurons in aMCl and AD cases compared to $\mathrm{NCl}$, including Cytcl, nuclear respiratory factor 1 (Nrf1), superoxide dismutase 2 (Sod2) and Gpx1, whereas Pfkl and platelet (Pfkp) isozymes were up-regulated in mild AD (red to green = decreasing expression levels). Additional abbreviations: superoxide dismutase 1 (Sod1), glutathione transferase (Gst), cytochrome p450 $11 \mathrm{a}$ (Cyp 11a), and pfk-muscle (Pfkm). c Heatmap shows significant decreases in transcripts regulating cytoskeletal/structural plasticity in LC neurons in aMCl and AD cases compared to NCl, including Map 1b, Nfh, integrin 3 (Itga3), netrin 1 (Ntn 1), utrophin (Utrn), and synaptopodin (Synpo), whereas calpain 1 (Capn1, m-calpain) and calpain 2 (Capn2, $\mu$-calpain) were up-regulated in mild AD (red to green = decreasing expression levels). Additional mRNAs: mitochondrial associated protein 2 (Map2), and synaptojanin (Synj). $a, \mathrm{NCl}>\mathrm{aMCl}, \mathrm{AD}, p<0.01 ; b, \mathrm{NCl}>\mathrm{aMCl}, \mathrm{AD}, p<0.001 ; c, \mathrm{AD}>\mathrm{NCl}$, $\mathrm{aMCl}, p<0.01$

neurons from $\mathrm{AD}$ subjects relative to $\mathrm{NCI}$ and $\mathrm{aMCI}$ (Fig. 3a, b).

Gene expression analysis also revealed a significant downregulation of transcripts related to neuritic/structural plasticity in cases with an antemortem clinical diagnosis of $\mathrm{aMCI}$ and $\mathrm{AD}$ compared to NCI, including mRNAs encoding microtubule associated binding protein 1b (Map 1b; $50 \% ; p<0.01)$, neurofilament heavy chain $(N f h ; 65 \% ; p<$ 0.001 ), cell surface adhesion molecule integrin alpha 3 subunit (Itga3; 55\%; $p<0.001$ ), axon guidance protein netrin (Ntn1; $40 \% ; p<0.01)$, postsynaptic clustering protein utrophin (Utrn; 45\%; $p<0.01$ ), and the dendritic spine plasticity protein synaptopodin (Synpo; 60\%; $p<0.01$ ) (Fig. 3a, c). Moreover, an analysis of transcripts encoding the six tau isoforms (Mapt1-Mapt6) [54] revealed a significant $~ 25-$ $30 \%$ decrease in the ratio of 3-repeat tau (3Rtau) to 4repeat tau (4Rtau) isoform expression within single LC neurons in aMCI and AD compared to NCI cases (Table 3). In contrast, an upregulation of the cytoskeletal proteases calpain 1 (Capn1; 45\%; $p<0.01)$ and calpain 2 (Capn2; $55 \% ; p<0.01$ ) was found in $\mathrm{AD}$ (Fig. 3c).
Several transcripts encoding other functional classes of genes relevant to AD pathogenesis were unaffected. For example, levels of amyloid- $\beta$ precursor protein $(A p p)$ and several genes related to APP metabolism, such as beta-site APP-cleaving enzyme 1 (Bace1), presenilin 1 (Psen1), and APP family member genes amyloid precursor-like protein 1 (Aplp1) and amyloid precursor-like protein 2 (Aplp2) were not differentially regulated in LC neurons across the clinical groups (Additional file 1: Figure S1).

\section{Correlations with clinical pathologic variables}

Although there were no associations between transcript levels and age or PMI, there was a strong relationship

Table 3 3Rtau/4Rtau mRNA ratios in single LC neurons

\begin{tabular}{llll}
\hline Clinical diagnosis & $\begin{array}{l}3 \mathrm{R} / 4 \mathrm{R} \text { ratio } \\
0 \text { insert }\end{array}$ & $\begin{array}{l}3 \mathrm{R} / 4 \mathrm{R} \text { ratio } \\
1 \text { insert }\end{array}$ & $\begin{array}{l}3 \mathrm{R} / 4 \mathrm{R} \text { ratio } \\
2 \text { inserts }\end{array}$ \\
\hline $\mathrm{NCl}$ & $1.36 \pm 0.11$ & $1.12 \pm 0.14$ & $1.25 \pm 0.07$ \\
$\mathrm{aMCl}$ & $1.02 \pm 0.09^{*}$ & $0.81 \pm 0.08^{*}$ & $0.92 \pm 0.12^{*}$ \\
$\mathrm{AD}$ & $0.98 \pm 0.1^{*}$ & $0.83 \pm 0.05^{*}$ & $0.89 \pm 0.13^{*}$
\end{tabular}

${ }^{*} p<0.05$ via one-way ANOVA with Bonferroni correction 
between downregulation of LC metabolic and structural plasticity gene expression and decreased GCS performance (Fig. 4) [14]. The four strongest associations were between GCS and Cytc1 $(p<0.0001$, Fig. 4a), Nrf1 ( $p=$ 0.0003 , Fig. 4b), Map1b ( $p=0.0006$, Fig. 4c) and Synpo $(p<0.0001$, Fig. 4 d) transcripts. There were also significant associations between metabolic and structural plasticity gene expression and MMSE scores (Table 4). By comparison, stable levels of superoxide dismutase 1 (Sod1; Fig. 3b) were not associated with GCS or MMSE scores across diagnostic groups. Virtually all of these select transcript reductions correlated negatively with increasing measures of neuropathology (Braak, NIAReagan, and CERAD diagnostic criteria; Table 4).

\section{Microarray validation}

Since all brainstem tissue containing the LC from the RROS cohort is immersion-fixed [106, 120], qPCR and immunoblot validation analyses of frozen tissue samples were not conducted as previously described $[4,27,53]$. However, changes associated with the noradrenergic phenotype at the single neuron level would likely be masked by regional expression patterns from admixed neuronal and non-neuronal cell types included in the frozen samples required for these analyses, similar to our observations in cholinergic neurons in the nucleus basalis/substantia innominata $[28,30,54]$. On the other hand, studies using regional gene expression analysis or neuronal immunohistochemical analysis in vulnerable brain regions have reported findings that support our LCM-based custom microarray approach. For instance, Map1b gene expression was downregulated in AD temporal cortex [123], whereas downregulation of Synpo protein in dendritic spines occurred in frontal cortex neurons in AD [9] similar to that found in our LC gene array experiments. Future studies employing single population RNA-sequencing, Fluidigm, and/or Nanostring nCounter analyses are warranted when transcriptomic technologies become more standardized and economical $[22,66,73]$.

\section{Discussion}

We demonstrate in this report that $\mathrm{TH}$-ir, presumably noradrenergic LC neurons are vulnerable during the onset of dementia as evidenced by their loss in aMCI and $\mathrm{AD}$ and the association of this loss with multiple measures of cognitive deterioration and neuropathological accumulation. We further characterized the molecular underpinnings of LC neuronal vulnerability by single population microarray analysis. Results indicated selective changes in genes regulating mitochondrial function and neuritic/structural plasticity, which also correlated with antemortem cognitive status and postmortem plaque and tangle burden. Hence, the
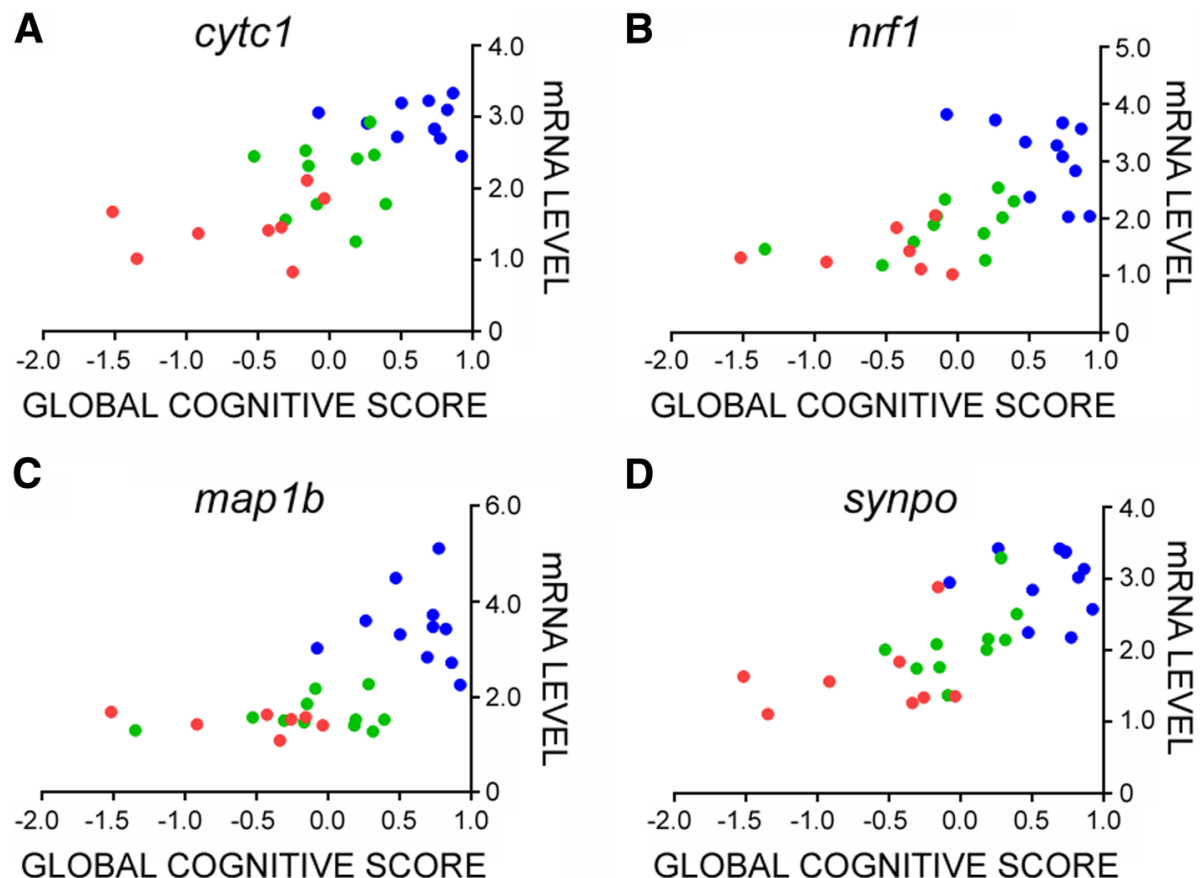

Fig. 4 Alterations in select transcripts isolated from noradrenergic $L C$ neurons correlate with global cognition during the progression of AD. Scatterplots show significant relationships between decreasing levels of a Cytc1 ( $r=0.64, p<0.0001)$, b Nrf1 $(r=0.57, p=0.0003)$, c Map 1b ( $r=0.59$, $p=0.0006)$, and $\mathbf{d}$ Synpo $(r=0.65, p<0.0001)$ and worsening GCS score, via Spearman rank correlation analysis. Symbols: $\mathrm{NCl}$ (blue-filled circle), aMCl (green-filled circle), AD (red-filled circle) 
Table 4 Clinical pathologic correlations of select LC neuronal transcripts dysregulated in aMCI and AD

\begin{tabular}{llllll}
\hline transcript & GCS & MMSE & Braak & NIA-Reagan & CERAD \\
\hline cytc1 & $r=0.64(p<0.0001)$ & $r=0.48(p=0.003)$ & $r=-0.50(p=0.003)$ & $r=-0.41(p=0.02)$ & $r=-0.48(p=0.01)$ \\
nrf1 & $r=0.57(p=0.0003)$ & $r=0.37(p=0.04)$ & $r=-0.43(p=0.08)$ & $r=-0.39(p=0.06)$ & $r=-0.50(p=0.003)$ \\
gpx1 & $r=0.54(p=0.008)$ & $r=0.44(p=0.008)$ & $r=-0.42(p=0.02)$ & $r=-0.42(p=0.01)$ & $r=-0.39(p=0.02)$ \\
map1b & $r=0.59(p=0.0006)$ & $r=0.35(p=0.03)$ & $r=-0.43(p=0.01)$ & $r=-0.33(p=0.2)$ & $r=-0.32(p=0.09)$ \\
nf-h & $r=0.54(p=0.0007)$ & $r=0.51(p=0.001)$ & $r=-0.55(p<0.001)$ & $r=-0.49(p=0.005)$ & $r=-0.45(p=0.006)$ \\
ntn1 & $r=0.52(p=0.0008)$ & $r=0.44(p=0.007)$ & $r=-0.41(p<0.01)$ & $r=-0.40(p=0.02)$ & $r=-0.47(p=0.006)$ \\
synpo & $r=0.65(p<0.0001)$ & $r=0.52(p<0.001)$ & $r=-0.58(p<0.001)$ & $r=-0.47(p=0.008)$ & $r=-0.45(p=0.005)$ \\
sod1 & $r=0.22(p=0.1)$ & $r=-0.11(p=0.5)$ & $r=-0.18(p=0.6)$ & $r=-0.09(p=0.6)$ & $r=-0.28(p=0.1)$ \\
\hline
\end{tabular}

early loss of forebrain monoaminergic signaling mediated by the LC appears to be central to AD pathophysiology.

Rodent and non-human primate investigations have revealed the importance of the ascending noradrenergic LC projection system for cognitive function [11, 16, 85]. Based on a series of seminal experiments, Aston-Jones and Cohen proposed a theory of 'adaptive gain' whereby NE integrates sensory, attentional and memory processing by positively modulating signal gain in neurons to facilitate the processing of salient events by driving LC phasic activity in response to relevant stimuli [11]. LC bursts and pulsatile NE efflux in coeruleus target fields (e.g., hippocampus and prefrontal cortex) increases the activity of excitatory inputs and decreases the action of inhibitory inputs, which optimizes task performance [11, 16]. Despite the more caudal location of the LC deep within the brainstem it might be envisioned as the brain's "watchtower," scanning incoming sensory information for important events that require immediate attention [33]. Moreover, NE-dependent modulation of long-term alterations in synaptic strength and gene transcription, particularly within the hippocampus and prefrontal cortex, influences memory formation and experience-dependent alterations in neural function and behavior and plays a critical role in the ability of the LC to optimize performance [105]. Finally, evidence from transgenic mouse models of $\mathrm{AD}$ and neuronal cell culture studies show that NE exerts a wide array of neuroprotective effects including anti-inflammatory and proneurotrophic mechanisms $[32,43,44,58,64,72,74$, 117]. Taken together, these data suggest that the central $\mathrm{NE}$ projection system is essential for cognitive function and, in turn, that LC neuronal degeneration contributes to cognitive dysfunction.

Recently, two reports have shown that LC neurodegeneration coincides with both mounting Braak stage pathology [110] and cognitive impairment [7]. Theofilas and colleagues reported that LC volume decreases $\sim 8.4 \%$ with each successive Braak stage, resulting in a significant $\sim 25 \%$ loss of LC volume between control cases neuropathologically diagnosed postmortem as Braak stage III compared to stage 0 [110]. This volume loss mirrored a similar rate of change in total pigmented and non-pigmented LC neuron numbers, as measured by unbiased stereology [110]. The authors also noted that the topography of LC volume and cell loss appears to follow a rostrocaudal gradient similar to that reported in frank $\mathrm{AD}$ cases $[49,110]$. Here, we report that the loss of TH-ir, presumably noradrenergic LC neurons also correlates with Braak stage. In addition, we found that $\mathrm{TH}$-ir neuron loss correlated with increasing neuropathologic burden based on NIA-Reagan and CERAD diagnostic criteria. As reductions in LC neuron number have been associated with increased cortical amyloid plaque and NFT loads in cases of frank AD $[18,108]$, these observations in early stage cases indicate a strong relationship between LC projection system degeneration and the pathologic sequela of AD.

Arendt and colleagues used unbiased stereology to demonstrate a significant $\sim 13 \%$ loss of neuromelaninpositive LC neurons in subjects classified as $\mathrm{MCI} /$ prodromal AD (CDR 0.5 who also displayed "low" to "intermediate" amyloid-Braak-CERAD (ABC) diagnostic scores [61]) compared to those classified as controls (CDR 0 and "not" ABC score) [7]. Subjects classified as mild/moderate AD exhibited $~ 30-45 \%$ LC cell loss compared to controls. This study revealed that LC cell loss, which is prominent in cases of frank AD [19, 24, 36, 75, $86,119]$, appears to occur early in the clinical progression of $\mathrm{AD}$, concurrent with cell loss in the nucleus basalis and entorhinal cortex [7].

The present morphometric analysis revealed a 30\% loss of TH-ir LC number during the transition from $\mathrm{NCI}$ to aMCI in cases classified independent of neuropathological diagnosis. Notably, our estimate of total TH-ir LC cell number in $\mathrm{NCI} /$ healthy controls $(19,495 \pm 2,891)$ was similar to other studies [23, 50, 93, 112] and, more specifically, to Arendt and colleagues' unbiased estimate of total neuromelaninpositive neurons $(17,487 \pm 2,736)$ for this group. The discrepancy in the observed loss of LC neurons 
between control and $\mathrm{MCI} /$ prodromal $\mathrm{AD}$ between these two studies ( $\sim 30 \%$ compared to $\sim 13 \%)$ could be related to cohort group classifications or possibly to a relatively greater loss of TH-expressing neurons compared to neuromelanin-positive neurons early in the disease process. In this regard, it would be interesting to determine whether a subset of neuromelaninpositive LC neurons undergoes a phenotypic downregulation of $\mathrm{TH}$ during the disease. Regardless, the present findings suggest that a disconnection of transmitter-identified LC projections to the forebrain contributes to the presentation of clinical disease.

With respect to the relationship between LC degeneration and cognitive status across the diagnostic groups, we found that reduced numbers of TH-ir LC neurons were associated not only with episodic memory deficits that define aMCI subtypes [63], but also with semantic memory, working memory, perceptual speed, and visuospatial ability. Since the LC innervates components of the dorsal memory network (e.g., dorsolateral and dorsomedial prefrontal cortex) $[10,84]$ and the amygdala $[46,99,115]$, which are both dysfunctional early in the onset of AD [89], disruption of NE afferents to these structures may play a role in the deficits seen in these various cognitive domains [14]. In fact, we found that quantitative decreases in LC neuron number were associated with poorer performance on measures of global cognitive function, as well. Hence, we demonstrate a link between loss of noradrenergic tone, neuropathological criteria, and cognitive decline. However, regression analysis revealed that global cognitive decline, but not neuropathological status, was a predictor for LC cell number. These findings lend support to a previous autopsy study, which showed that higher LC neuronal density was associated with slower rates of antemortem cognitive decline, suggesting a role for the LC in cognitive reserve [120]. Altogether, our data supports an emerging theory that LC neuron degeneration is an early pathological event that contributes to cognitive dysfunction and the onset of $\mathrm{AD}$, and is likely a site for therapeutic intervention.

The cellular and molecular mechanisms underlying LC selective vulnerability in the early stages of $A D$ are unclear. To begin to address this question, we profiled gene expression patterns of transmitter-identified LC neurons microdissected from $\mathrm{NCI}, \mathrm{aMCI}$, and $\mathrm{AD}$ cases. We noted two major patterns of expression changes related to functional classes of genes regulating mitochondrial function and neuritic plasticity. With respect to the transcripts involved in mitochondrial dysfunction, Nrf1 and Cytc1 mRNA levels were both significantly downregulated in LC neurons in aMCI and mild AD relative to NCI. Nrf1 is a transcription factor that directs the expression of several functional classes of genes involved in mitochondrial function, including those regulating redox homeostasis, mitochondrial biogenesis, calcium homeostasis, and cytochrome oxidase activity [17, 40, 41]. Interestingly, Cytc1 is the hemecontaining component in the cytochrome b-c1 complex III of the respiratory chain, accepting electrons from Rieske protein and transferring it to cytochrome c, which couples to cytochrome oxidase $[47,113]$. By contrast, transcript levels of $P f k l$ and $P f k p$ isozymes were significantly upregulated in LC neurons in AD. These enzyme subunits catalyze the conversion of D-fructose 6-phosphate to D-fructose 1,6-bisphosphate, resulting in the first committing step of glycolysis [60]. Taken together, these results indicate that $\mathrm{LC}$ neurons are under considerable respiratory stress during the transition from NCI to prodromal and frank AD. In addition, these neurons displayed significant decreases in transcripts encoding the antioxidant enzymes mitochondrial Sod2 and Gpx1 in aMCI. Given the role of these two enzymes in detoxifying superoxide and hydrogen peroxide, respectively, LC neurons are also likely under considerable oxidative stress prior to the onset of aMCI [109]. These observations support tissue-based assessments demonstrating regional mitochondrial deficits during the progression of $\mathrm{AD}[12,15,59,71,101,102$, $116,125]$, but importantly, identify these changes in neurons, as opposed to glial cells or admixed populations of cells, thus attributing these markers for mitochondrial dysfunction to LC neurons.

A second common thread of transcript dysregulation in aMCI centered on genes encoding proteins involved in axonal function and neuronal morphological plasticity. For instance, Map1b is critical for microtubule stabilization during axonal growth [114] and Ntn1 plays a role in axonal guidance [81], whereas $\mathrm{Nfh}$ is essential in maintaining axonal caliber and is dysregulated in human AD and animal models of the disease [42, 83]. Significant downregulation of these genes suggest that LC neurons may be undergoing an axonal degenerative process during prodromal stages, which progress to frank $A D$ as evidenced by a significant increase in the cytoskeletal proteases Capn1 and Capn2 expression in AD neurons [92, 104]. Moreover, we found a global decrease in the ratio of $3 \mathrm{R} / 4 \mathrm{R}$ tau isoforms in $\mathrm{LC}$ neurons in aMCI and $\mathrm{AD}$, consistent with previous single cell gene expression studies of cholinergic nucleus basalis and CA1 pyramidal neurons isolated from $\mathrm{MCI}$ and $\mathrm{AD}$ cases [54]. The alteration in $3 \mathrm{R}$ tau gene dosage relative to $4 \mathrm{R}$ tau suggests a shift toward tau isoforms associated with slower axonal transport kinetics as well as NFT formation $[37,69,107]$.

Finally, we observed a concomitant downregulation of genes encoding the postsynaptic receptor clustering protein Utrn and the dendritic spine marker Synpo in aMCI and 
AD neurons compared to NCI. In particular, Synpo is an actin-associated protein that may play a role in modulating actin-based shape and motility of dendritic spines and seems to be essential for the formation of spine apparatuses involved in synaptic plasticity [39, 68]. Dysregulation of postsynaptic gene expression in vulnerable LC neurons may signal perturbations prior to the onset of aMCI that are indicative of a failure in neuroplastic and/or remodeling programs [38, 39, 68, 89]. While we cannot rule out the possibility that these molecular changes are epiphenomenal to $\mathrm{AD}$ pathogenesis, the timing of these changes to stages prior to the onset of aMCI suggest that they represent pathways critical to disease progression.

Perhaps the most striking feature of the LC is the immensity and divergence of its noradrenergic forebrain efferents [45], extensive complex dendritic arborization pattern, and the long distance these perikarya project to reach their forebrain innervation sites $[6,8,85]$. In this regard, LC neurons are similar to other selectively vulnerable long forebrain projection neuron systems (e.g., cholinergic basal forebrain neurons, substantia nigra pars compacta neurons, and dorsal raphe neurons, among others $[5,16,78,80,105])$, that are heavily reliant on energy metabolism and cytoskeletal integrity to modulate synaptic input. These long projection systems are likely more prone to cellular stress given their position in the brain's organization. Taken together, our findings present evidence for the molecular dysregulation of mitochondrial function and neuritic/structural plasticity coinciding with the loss of LC neurons prior to the transition from NCI to prodromal AD. Moreover, our observation that the dysregulation of these genes correlates with poorer global cognition and greater neuropathological burden suggests that these molecular pathways represent pathogenic mechanisms underlying the selective vulnerability of LC neurons which may be common to other vulnerable neurons. Notably, there is evidence from similar single neuron expression analysis studies showing alterations in mitochondrial and structural plasticity pathways in AD. For instance, we have demonstrated that cholinergic nucleus basalis neurons exhibit alterations in Sod2, Pfkl, and Capn1 in AD [29]. Other studies have also demonstrated an AD-related dysregulation of specific respiratory chain genes (e.g., cytochrome oxidase $5 \mathrm{~b}$ ) in medial temporal and posterior cingulate pyramidal neurons [70, 71]. However, the extent to which dysregulation of these pathways are evident in other selectively vulnerable cell groups during the onset of cognitive decline warrants further comparative assessments of these neuron groups as well as relatively unaffected populations in postmortem brain tissues. Moreover, whether dysregulation of these pathways is related to NFT or Lewy body pathology in these neurons is an additional question to be addressed in future studies
[51, 55, 62, 111, 112]. The current findings also suggest the need for additional quantitative biochemical and immunohistochemical assessments of these mitochondrial and structural markers in LC neurons in aMCI.

\section{Conclusions}

The present findings point to the continuing need to consider noradrenergic system pathophysiology as a key and early component associated with the progression of $\mathrm{AD}$. We posit that strategies aimed at LC neuroprotection or NE replacement are viable therapeutic options [98]. Moreover, as prominent LC degeneration is also evident in cases of Parkinson's disease with dementia and dementia with Lewy bodies [57], maintaining LC projection system integrity may provide a common therapeutic mechanism for combating cognitive decline in multiple late-onset dementia subtypes. Here, we present several candidate molecular pathways that are dysregulated in LC neurons early in the cascade of pathogenic events prior to the onset of $\mathrm{AD}$, which may form the basis for novel neuroprotective approaches for dementia.

\section{Additional file}

Additional file 1: Figure S1. No change in AD-related gene expression in LC neurons during disease progression. Bar graph shows changes in App, Bacel, Psen1, Aplp1, and Aplp2 transcripts in aMCl and $\mathrm{AD}$ relative to $\mathrm{NCl}$. No significant differences were calculated across the diagnostic groups. (TIF $998 \mathrm{~kb}$ )

\section{Acknowledgements}

We are indebted to the Catholic nuns, priests, and brothers who participated in the Rush Religious Orders Study and to the members of the Rush ADC.

\section{Funding}

This study was supported by grants AG014449, AG043375, AG010161, and AG042146 from the National Institute on Aging, National Institutes of Health; the Saint Mary's Foundation; Miles for Memories of Battle Creek, Ml; and Barrow Neurological Institute Barrow and Beyond.

\section{Availability of data and materials}

The datasets used and/or analyzed during the current study are available from the corresponding author on reasonable request.

\section{Authors' contributions}

SCK was instrumental in both morphometric and gene expression data analysis and was the major contributor in writing the manuscript. BH was instrumental in performing the laser capture and gene expression analysis. SEP was instrumental in tissue processing and in the design of the stereologic parameters. SDG designed and produced the custom microarray platform, assisted in the analysis of the gene expression data, and was a contributor in writing the manuscript. EJM was instrumental in study design, tissue selection, analysis and interpretation of the morphometric data, and was a contributor in writing the manuscript. SEC led the study design, performed the morphometric analysis, assisted in laser capture and gene expression analysis, oversaw all data analysis and interpretation, and was a major contributor in writing the manuscript. All authors read and approved the final manuscript.

\section{Competing interests}

The authors declare that they have no competing interests.

Consent for publication

Not applicable. 


\section{Ethics approval and consent to participate}

The study was determined to be exempt from human subjects review by the Rush University Medical Center and Michigan State University Institutional Review Boards. All procedures were performed in accordance with the ethical standards of the institutions and with the 1964 Helsink declaration and its later amendments.

\section{Author details}

'Department of Translational Science and Molecular Medicine, Michigan State University, 333 Bostwick Ave NE, Grand Rapids, MI 49503, USA. ${ }^{2}$ Cell and Molecular Biology Program, Michigan State University, East Lansing, MI, USA. ${ }^{3}$ Department of Family Medicine, Michigan State University, East Lansing, MI, USA. ${ }^{4}$ Hauenstein Neurosciences Center, Mercy Health Saint Mary's Hospital, Grand Rapids, MI, USA. ${ }^{5}$ Department of Neurobiology, Barrow Neurological Institute, Phoenix, AZ, USA. ${ }^{6}$ Center for Dementia Research, Nathan Kline Institute, Orangeburg, NY, USA. ${ }^{7}$ Department of Psychiatry, New York University Langone School of Medicine, New York, NY, USA.

${ }^{8}$ Department of Neuroscience and Physiology, New York University Langone School of Medicine, New York, NY, USA.

Received: 7 January 2017 Accepted: 8 January 2017

Published online: 21 January 2017

\section{References}

1. Adolfsson R, Gottfries CG, Roos BE, Winblad B (1979) Changes in the brain catecholamines in patients with dementia of Alzheimer type. $\mathrm{Br}$ J Psychiatry 135:216-223

2. Albert MS, Dekosky ST, Dickson D, Dubois B, Feldman HH, Fox NC, Gamst A, Holtzman DM, Jagust WJ, Petersen RC, Snyder PJ, Carrillo MC, Thies B, Phelps CH (2011) The diagnosis of mild cognitive impairment due to Alzheimer's disease: Recommendations from the National Institute on Aging-Alzheimer's Association workgroups on diagnostic guidelines for Alzheimer's disease. Alzheimers Dement 7:270-279

3. Alldred MJ, Che S, Ginsberg SD (2009) Terminal continuation (TC) RNA amplification without second strand synthesis. J Neurosci Methods 177:381-385

4. Alldred MJ, Duff KE, Ginsberg SD (2012) Microarray analysis of CA1 pyramidal neurons in a mouse model of tauopathy reveals progressive synaptic dysfunction. Neurobiol Dis 45:751-762

5. Arendt T (2000) Alzheimer's disease as a loss of differentiation control in a subset of neurons that retain immature features in the adult brain. Neurobiol Aging 21:783-796

6. Arendt T, Bruckner MK, Bigl V, Marcova L (1995) Dendritic reorganisation in the basal forebrain under degenerative conditions and its defects in Alzheimer's disease. III. The basal forebrain compared with other subcortical areas. J Comp Neurol 351:223-246

7. Arendt T, Bruckner MK, Morawski M, Jager C, Gertz HJ (2015) Early neurone loss in Alzheimer's disease: cortical or subcortical? Acta Neuropathol Commun 3:10. doi:10.1186/s40478-015-0187-1

8. Arendt T, Schindler C, Bruckner MK, Eschrich K, Bigl V, Zedlick D, Marcova L (1997) Plastic neuronal remodeling is impaired in patients with Alzheimer's disease carrying apolipoprotein epsilon 4 allele. J Neurosci 17:516-529

9. Arnold SE, Louneva N, Cao K, Wang LS, Han LY, Wolk DA, Negash S, Leurgans SE, Schneider JA, Buchman AS, Wilson RS, Bennett DA (2012) Cellular, synaptic, and biochemical features of resilient cognition in Alzheimer's disease. Neurobiol Aging 34:157-168

10. Arnsten AF, Goldman-Rakic PS (1984) Selective prefrontal cortical projections to the region of the locus coeruleus and raphe nuclei in the rhesus monkey. Brain Res 306:9-18

11. Aston-Jones G, Cohen JD (2005) An integrative theory of locus coeruleusnorepinephrine function: adaptive gain and optimal performance. Annu Rev Neurosci 28:403-450

12. Beck JS, Mufson EJ, Counts SE (2015) Evidence for mitochondrial UPR gene activation in familial and sporadic Alzheimer's disease. Curr Alzheimer Res 13:610-614.

13. Bennett DA, Schneider JA, Bienias JL, Evans DA, Wilson RS (2005) Mild cognitive impairment is related to Alzheimer disease pathology and cerebral infarctions. Neurology 64:834-841

14. Bennett DA, Wilson RS, Schneider JA, Evans DA, Beckett LA, Aggarwal NT, Barnes LL, Fox JH, Bach J (2002) Natural history of mild cognitive impairment in older persons. Neurology 59:198-205
15. Berchtold NC, Sabbagh MN, Beach TG, Kim RC, Cribbs DH, Cotman CW (2014) Brain gene expression patterns differentiate mild cognitive impairment from normal aged and Alzheimer's disease. Neurobiol Aging 35:1961-1972

16. Berridge CW, Waterhouse BD (2003) The locus coeruleus-noradrenergic system: modulation of behavioral state and state-dependent cognitive processes. Brain Res Brain Res Rev 42:33-84

17. Biswas M, Chan JY (2010) Role of Nrf1 in antioxidant response elementmediated gene expression and beyond. Toxicol Appl Pharmacol 244:16-20

18. Bondareff W, Mountjoy CQ, Roth M, Rossor MN, Iversen LL, Reynolds GP, Hauser DL (1987) Neuronal degeneration in locus ceruleus and cortical correlates of Alzheimer disease. Alzheimer Dis Assoc Disord 1:256-262

19. Bondareff W, Mountjoy CQ, Roth M (1981) Selective loss of neurones of origin of adrenergic projection to cerebral cortex (nucleus locus coeruleus) in senile dementia. Lancet 1:783-784

20. Braak H, Braak E (1991) Neuropathological stageing of Alzheimer-related changes. Acta Neuropathol 82:239-259

21. Braak H, Del Tredici K (2011) The pathological process underlying Alzheimer's disease in individuals under thirty. Acta Neuropathol 121:171-181

22. Buettner F, Natarajan KN, Casale FP, Proserpio V, Scialdone A, Theis FJ, Teichmann SA, Marioni JC, Stegle O (2015) Computational analysis of cellto-cell heterogeneity in single-cell RNA-sequencing data reveals hidden subpopulations of cells. Nat Biotechnol 33:155-160

23. Busch C, Bohl J, Ohm TG (1997) Spatial, temporal and numeric analysis of Alzheimer changes in the nucleus coeruleus. Neurobiol Aging 18:401-406

24. Chan-Palay V, Asan E (1989) Alterations in catecholamine neurons of the locus coeruleus in senile dementia of the Alzheimer type and in Parkinson's disease with and without dementia and depression. J Comp Neurol 287:373-392

25. Chan-Palay V, Asan E (1989) Quantitation of catecholamine neurons in the locus coeruleus in human brains of normal young and older adults and in depression. J Comp Neurol 287:357-372

26. Che S, Ginsberg SD (2004) Amplification of RNA transcripts using terminal continuation. Lab Invest 84:131-137

27. Counts SE, Alldred MJ, Che S, Ginsberg SD, Mufson EJ (2013) Synaptic gene dysregulation within hippocampal CA1 pyramidal neurons in mild cognitive impairment. Neuropharmacology 79C:172-179.

28. Counts SE, He B, Che S, Ginsberg SD, Mufson EJ (2008) Galanin hyperinnervation upregulates choline acetyltransferase expression in cholinergic basal forebrain neurons in Alzheimer's disease. Neurodegener Dis 5:228-231.

29. Counts SE, He B, Che S, Ginsberg SD, Mufson EJ (2009) Galanin fiber hyperinnervation preserves neuroprotective gene expression in cholinergic basal forebrain neurons in Alzheimer's disease. J Alzheimers Dis 18:885-896

30. Counts SE, Chen EY, Che S, Ikonomovic MD, Wuu J, Ginsberg SD, Dekosky ST, Mufson EJ (2006) Galanin fiber hypertrophy within the cholinergic nucleus basalis during the progression of Alzheimer's disease. Dement Geriatr Cogn Disord 21:205-214.

31. Counts SE, He B, Che S, Ikonomovic MD, DeKosky ST, Ginsberg SD, Mufson EJ (2007) Alpha7 nicotinic receptor up-regulation in cholinergic basal forebrain neurons in Alzheimer disease. Arch Neurol 64:1771-1776

32. Counts SE, Mufson EJ (2010) Noradrenaline activation of neurotrophic pathways protects against neuronal amyloid toxicity. J Neurochem 113:649-660

33. Counts SE, Mufson EJ (2012) Locus coeruleus. In: Mai JK, Paxinos G (eds) The human nervous system, 3rd edn. Academic, London, pp 425-438

34. Counts SE, Nadeem M, Lad SP, Wuu J, Mufson EJ (2006) Differential expression of synaptic proteins in the frontal and temporal cortex of elderly subjects with mild cognitive impairment. J Neuropathol Exp Neurol 65:592-601

35. Dahlstroem A, Fuxe K (1964) Evidence for the existence of monoaminecontaining neurons in the central nervous system. I. Demonstration of monoamines in the cell bodies of brain stem neurons. Acta Physiol Scand Suppl:SUPPL 232:231-255

36. Davies P, Maloney AJ (1976) Selective loss of central cholinergic neurons in Alzheimer's disease. Lancet 2:1403

37. de Silva R, Lashley T, Gibb G, Hanger D, Hope A, Reid A, Bandopadhyay R, Utton M, Strand C, Jowett T, Khan N, Anderton B, Wood N, Holton J, Revesz T, Lees A (2003) Pathological inclusion bodies in tauopathies contain distinct complements of tau with three or four microtubule-binding repeat domains as demonstrated by new specific monoclonal antibodies. Neuropathol Appl Neurobiol 29:288-302 
38. Deconinck AE, Potter AC, Tinsley JM, Wood SJ, Vater R, Young C, Metzinger L, Vincent A, Slater CR, Davies KE (1997) Postsynaptic abnormalities at the neuromuscular junctions of utrophin-deficient mice. J Cell Biol 136:883-894

39. Deller T, Korte M, Chabanis S, Drakew A, Schwegler H, Stefani GG, Zuniga A, Schwarz K, Bonhoeffer T, Zeller R, Frotscher M, Mundel P (2003) Synaptopodin-deficient mice lack a spine apparatus and show deficits in synaptic plasticity. Proc Natl Acad Sci U S A 100:10494-10499

40. Dhar SS, Liang HL, Wong-Riley MT (2009) Nuclear respiratory factor 1 coregulates AMPA glutamate receptor subunit 2 and cytochrome c oxidase: tight coupling of glutamatergic transmission and energy metabolism in neurons. J Neurochem 108:1595-1606

41. Dhar SS, Ongwijitwat S, Wong-Riley MT (2008) Nuclear respiratory factor 1 regulates all ten nuclear-encoded subunits of cytochrome c oxidase in neurons. J Biol Chem 283:3120-3129

42. Elder GA, Friedrich VL Jr, Kang C, Bosco P, Gourov A, Tu PH, Zhang B, Lee VM, Lazzarini RA (1998) Requirement of heavy neurofilament subunit in the development of axons with large calibers. J Cell Biol 143:195-205

43. Feinstein DL, Heneka MT, Gavrilyuk V, Dello Russo C, Weinberg G, Galea E (2002) Noradrenergic regulation of inflammatory gene expression in brain. Neurochem Int 41:357-365

44. Feinstein DL, Kalinin S, Braun D (2016) Causes, consequences, and cures for neuroinflammation mediated via the locus coeruleus: noradrenergic signaling system. J Neurochem 139(Suppl 2):154-178

45. Foote SL (1997) The primate locus coeruleus: the chemcial neuroanatomy of the nucleus, its efferent projection, and its target receptors. In: Bloom FE, Bjorklund A, Hokfelt T (eds) Handbook of chemical neuroanatomy, vol 13. Elsevier, Amsterdam, pp 187-210

46. Foote SL, Bloom FE, Aston-Jones G (1983) Nucleus locus ceruleus: new evidence of anatomical and physiological specificity. Physiol Rev 63:844-914

47. Fornuskova D, Stiburek L, Wenchich L, Vinsova K, Hansikova H, Zeman J (2010) Novel insights into the assembly and function of human nuclear-encoded cytochrome c oxidase subunits 4, 5a, 6a, 7a and 7b. Biochem J 428:363-374

48. Forstl H, Levy R, Burns A, Luthert P, Cairns N (1994) Disproportionate loss of noradrenergic and cholinergic neurons as cause of depression in Alzheimer's disease-a hypothesis. Pharmacopsychiatry 27:11-15

49. German DC, Manaye KF, White CL 3rd, Woodward DJ, McIntire DD, Smith WK, Kalaria RN, Mann DM (1992) Disease-specific patterns of locus coeruleus cell loss. Ann Neurol 32:667-676

50. German DC, Walker BS, Manaye K, Smith WK, Woodward DJ, North AJ (1988) The human locus coeruleus: computer reconstruction of cellular distribution. J Neurosci 8:1776-1788

51. German DC, White CL 3rd, Sparkman DR (1987) Alzheimer's disease: neurofibrillary tangles in nuclei that project to the cerebral cortex. Neuroscience 21:305-312

52. Ginsberg SD (2005) RNA amplification strategies for small sample populations. Methods 37:229-237

53. Ginsberg SD, Alldred MJ, Counts SE, Cataldo AM, Neve RL, Jiang Y, Wuu J, Chao MV, Mufson EJ, Nixon RA, Che S (2010) Microarray analysis of hippocampal CA1 neurons implicates early endosomal dysfunction during Alzheimer's disease progression. Biol Psychiatry 68:885-893

54. Ginsberg SD, Che S, Counts SE, Mufson EJ (2006) Shift in the ratio of threerepeat tau and four-repeat tau mRNAs in individual cholinergic basal forebrain neurons in mild cognitive impairment and Alzheimer's disease. J Neurochem 96:1401-1408

55. Grudzien A, Shaw P, Weintraub S, Bigio E, Mash DC, Mesulam MM (2007) Locus coeruleus neurofibrillary degeneration in aging, mild cognitive impairment and early Alzheimer's disease. Neurobiol Aging 28:327-335

56. Gundersen HJ, Bendtsen TF, Korbo L, Marcussen N, Moller A, Nielsen K, Nyengaard JR, Pakkenberg B, Sorensen FB, Vesterby A et al (1988) Some new, simple and efficient stereological methods and their use in pathological research and diagnosis. Apmis 96:379-394

57. Haglund M, Friberg N, Danielsson EJ, Norrman J, Englund E (2016) A methodological study of locus coeruleus degeneration in dementing disorders. Clin Neuropathol 35:287-294

58. Heneka MT, Galea E, Gavriluyk V, Dumitrescu-Ozimek L, Daeschner J, O'Banion MK, Weinberg G, Klockgether T, Feinstein DL (2002) Noradrenergic depletion potentiates beta -amyloid-induced cortical inflammation: implications for Alzheimer's disease. J Neurosci 22:2434-2442

59. Hirai $K$, Aliev G, Nunomura A, Fujioka H, Russell RL, Atwood CS, Johnson AB, Kress Y, Vinters HV, Tabaton M, Shimohama S, Cash AD, Siedlak SL, Harris PL,
Jones PK, Petersen RB, Perry G, Smith MA (2001) Mitochondrial abnormalities in Alzheimer's disease. J Neurosci 21:3017-3023

60. Hue L, Rider MH (1987) Role of fructose 2,6-bisphosphate in the control of glycolysis in mammalian tissues. Biochem J 245:313-324

61. Hyman BT, Phelps CH, Beach TG, Bigio EH, Cairns NJ, Carrillo MC, Dickson DW, Duyckaerts C, Frosch MP, Masliah E, Mirra SS, Nelson PT, Schneider JA, Thal DR, Thies B, Trojanowski JQ, Vinters HV, Montine TJ (2012) National Institute on Aging-Alzheimer's Association guidelines for the neuropathologic assessment of Alzheimer's disease. Alzheimers Dement 8:1-13

62. Ishizawa T, Mattila P, Davies P, Wang D, Dickson DW (2003) Colocalization of tau and alpha-synuclein epitopes in Lewy bodies. J Neuropathol Exp Neurol 62:389-397

63. Jacobs HI, Wiese S, van de Ven V, Gronenschild EH, Verhey FR, Matthews PM (2015) Relevance of parahippocampal-locus coeruleus connectivity to memory in early dementia. Neurobiol Aging 36:618-626

64. Kalinin S, Polak PE, Lin SX, Sakharkar AJ, Pandey SC, Feinstein DL (2012) The noradrenaline precursor L-DOPS reduces pathology in a mouse model of Alzheimer's disease. Neurobiol Aging 33:1651-1663

65. Kemper CM, O'Connor DT, Westlund KN (1987) Immunocytochemical localization of dopamine-beta-hydroxylase in neurons of the human brain stem. Neuroscience 23:981-989

66. Kim T, Lim CS, Kaang BK (2015) Cell type-specific gene expression profiling in brain tissue: comparison between TRAP, LCM and RNA-seq. BMB Rep 48:388-394

67. Kordower JH, Chu Y, Stebbins GT, DeKosky ST, Cochran EJ, Bennett D, Mufson EJ (2001) Loss and atrophy of layer II entorhinal cortex neurons in elderly people with mild cognitive impairment. Ann Neurol 49:202-213

68. Kremerskothen J, Plaas C, Kindler S, Frotscher M, Barnekow A (2005) Synaptopodin, a molecule involved in the formation of the dendritic spine apparatus, is a dual actin/alpha-actinin binding protein. J Neurochem 92:597-606

69. Levy SF, Leboeuf AC, Massie MR, Jordan MA, Wilson L, Feinstein SC (2005) Three- and four-repeat tau regulate the dynamic instability of two distinct microtubule subpopulations in qualitatively different manners. Implications for neurodegeneration. J Biol Chem 280:13520-13528

70. Liang WS, Dunckley T, Beach TG, Grover A, Mastroeni D, Ramsey K, Caselli RJ, Kukull WA, McKeel D, Morris JC, Hulette CM, Schmechel D, Reiman EM, Rogers J, Stephan DA (2010) Neuronal gene expression in non-demented individuals with intermediate Alzheimer's Disease neuropathology. Neurobiol Aging 31:549-566

71. Liang WS, Reiman EM, Valla J, Dunckley T, Beach TG, Grover A, Niedzielko TL, Schneider LE, Mastroeni D, Caselli R, Kukull W, Morris JC, Hulette CM, Schmechel D, Rogers J, Stephan DA (2008) Alzheimer's disease is associated with reduced expression of energy metabolism genes in posterior cingulate neurons. Proc Natl Acad Sci U S A 105:4441-4446

72. Liu X, Ye K, Weinshenker D (2015) Norepinephrine Protects against Amyloidbeta Toxicity via TrkB. J Alzheimers Dis 44:251-260

73. Macosko EZ, Basu A, Satija R, Nemesh J, Shekhar K, Goldman M, Tirosh I, Bialas AR, Kamitaki N, Martersteck EM, Trombetta JJ, Weitz DA, Sanes JR, Shalek AK, Regev A, McCarroll SA (2015) Highly parallel genome-wide expression profiling of individual cells using nanoliter droplets. Cell 161:1202-1214

74. Madrigal JL, Kalinin S, Richardson JC, Feinstein DL (2007) Neuroprotective actions of noradrenaline: effects on glutathione synthesis and activation of peroxisome proliferator activated receptor delta. J Neurochem 103:2092-2101

75. Mann DM, Lincoln J, Yates PO, Stamp JE, Toper S (1980) Changes in the monoamine containing neurones of the human CNS in senile dementia. $\mathrm{Br}$ J Psychiatry 136:533-541

76. Mann DM, Yates PO, Marcyniuk B (1984) A comparison of changes in the nucleus basalis and locus caeruleus in Alzheimer's disease. J Neurol Neurosurg Psychiatry 47:201-203

77. Markesbery WR, Schmitt FA, Kryscio RJ, Davis DG, Smith CD, Wekstein DR (2006) Neuropathologic substrate of mild cognitive impairment. Arch Neurol 63:38-46

78. Mattson MP, Magnus T (2006) Ageing and neuronal vulnerability. Nat Rev Neurosci 7:278-294

79. McKhann G, Drachman D, Folstein M, Katzman R, Price D, Stadlan EM (1984) Clinical diagnosis of Alzheimer's disease: report of the NINCDS-ADRDA Work Group under the auspices of Department of Health and Human Services Task Force on Alzheimer's Disease. Neurology 34:939-944

80. Mesulam MM (1999) Neuroplasticity failure in Alzheimer's disease: bridging the gap between plaques and tangles. Neuron 24:521-529

81. Metin C, Deleglise D, Serafini T, Kennedy TE, Tessier-Lavigne M (1997) A role for netrin-1 in the guidance of cortical efferents. Development 124:5063-5074 
82. Mirra SS, Heyman A, McKeel D, Sumi SM, Crain BJ, Brownlee LM, Vogel FS, Hughes JP, van Belle G, Berg L (1991) The Consortium to Establish a Registry for Alzheimer's Disease (CERAD). Part II. Standardization of the neuropathologic assessment of Alzheimer's disease. Neurology 41:479-486

83. Mitew S, Kirkcaldie MT, Dickson TC, Vickers JC (2013) Neurites containing the neurofilament-triplet proteins are selectively vulnerable to cytoskeletal pathology in Alzheimer's disease and transgenic mouse models. Front Neuroanat 7:30

84. Morrison JH, Foote SL, O'Connor D, Bloom FE (1982) Laminar, tangential and regional organization of the noradrenergic innervation of monkey cortex: dopamine-beta-hydroxylase immunohistochemistry. Brain Res Bull 9:309-319

85. Morrison JH, Molliver ME, Grzanna R (1979) Noradrenergic innervation of cerebral cortex: widespread effects of local cortical lesions. Science 205:313-316

86. Mufson EJ, Bothwell M, Kordower JH (1989) Loss of nerve growth factor receptor-containing neurons in Alzheimer's disease: a quantitative analysis across subregions of the basal forebrain. Exp Neurol 105:221-232

87. Mufson EJ, Chen EY, Cochran EJ, Beckett LA, Bennett DA, Kordower JH (1999) Entorhinal cortex beta-amyloid load in individuals with mild cognitive impairment. Exp Neurol 158:469-490

88. Mufson EJ, Binder LI, Counts SE, DeKosky ST, de Toledo-Morrell L, Ginsberg SD, Ikonomovic MD, Perez SE, Scheff, SW (2012) Mild cognitive impairment: pathology and mechanisms. Acta Neuropathol 123:13-30

89. Mufson EJ, Ikonomovic MD, Counts SE, Perez SE, Malek-Ahmadi M, Scheff SW, Ginsberg SD (2016) Molecular and cellular pathophysiology of preclinical Alzheimer's disease. Behav Brain Res 311:54-690

90. Mufson EJ, Ma SY, Cochran EJ, Bennett DA, Beckett LA, Jaffar S, Saragovi HU, Kordower JH (2000) Loss of nucleus basalis neurons containing trkA immunoreactivity in individuals with mild cognitive impairment and early Alzheimer's disease. J Comp Neurol 427:19-30

91. Mufson EJ, Ma SY, Dills J, Cochran EJ, Leurgans S, Wuu J, Bennett DA, Jaffar S, Gilmor ML, Levey Al, Kordower JH (2002) Loss of basal forebrain P75(NTR) immunoreactivity in subjects with mild cognitive impairment and Alzheimer's disease. J Comp Neurol 443:136-153

92. Nixon RA, Saito Kl, Grynspan F, Griffin WR, Katayama S, Honda T, Mohan PS, Shea TB, Beermann M (1994) Calcium-activated neutral proteinase (calpain) system in aging and Alzheimer's disease. Ann N Y Acad Sci 747:77-91

93. Ohm TG, Busch C, Bohl J (1997) Unbiased estimation of neuronal numbers in the human nucleus coeruleus during aging. Neurobiol Aging 18:393-399

94. Palmer AM, Wilcock GK, Esiri MM, Francis PT, Bowen DM (1987) Monoaminergic innervation of the frontal and temporal lobes in Alzheimer's disease. Brain Res 401:231-238

95. Perez SE, He B, Nadeem M, Wuu J, Scheff SW, Abrahamson EE, Ikonomovic MD, Mufson EJ (2015) Resilience of precuneus neurotrophic signaling pathways despite amyloid pathology in prodromal Alzheimer's disease. Biol Psychiatry 77:693-703

96. Petersen RC (2004) Mild cognitive impairment as a diagnostic entity. J Intern Med 256:183-194

97. Petersen RC, Doody R, Kurz A, Mohs RC, Morris JC, Rabins PV, Ritchie K, Rossor M, Thal L, Winblad B (2001) Current concepts in mild cognitive impairment. Arch Neurol 58:1985-1992

98. Phillips C, Fahimi A, Das D, Mojabi FS, Ponnusamy R, Salehi A (2016) Noradrenergic system in down syndrome and Alzheimer's disease a target for therapy. Curr Alzheimer Res 13:68-83

99. Price JL, Amaral DG (1981) An autoradiographic study of the projections of the central nucleus of the monkey amygdala. J Neurosci 1:1242-1259

100. Price $J$, Morris JC (1999) Tangles and plaques in nondemented aging and "preclinical" Alzheimer's disease. Ann Neurol 45:358-368

101. Reddy PH (2011) Abnormal tau, mitochondrial dysfunction, impaired axonal transport of mitochondria, and synaptic deprivation in Alzheimer's disease. Brain Res 1415:136-148

102. Reddy PH, Tripathi R, Troung Q, Tirumala K, Reddy TP, Anekonda V, Shirendeb UP, Calkins MJ, Reddy AP, Mao P, Manczak M (2012) Abnormal mitochondrial dynamics and synaptic degeneration as early events in Alzheimer's disease: implications to mitochondria-targeted antioxidant therapeutics. Biochim Biophys Acta 1822:639-649

103. Reiner A, Yekutieli D, Benjamini Y (2003) Identifying differentially expressed genes using false discovery rate controlling procedures. Bioinformatics 19:368-375

104. Riascos D, Nicholas A, Samaeekia R, Yukhananov R, Mesulam MM, Bigio EH, Weintraub S, Guo L, Geula C (2014) Alterations of Ca(2)(+)-responsive proteins within cholinergic neurons in aging and Alzheimer's disease. Neurobiol Aging 35:1325-1333
105. Sara SJ (2009) The locus coeruleus and noradrenergic modulation of cognition. Nat Rev Neurosci 10:211-223

106. Schneider JA, Bienias JL, Gilley DW, Kvarnberg DE, Mufson EJ, Bennett DA (2002) Improved detection of substantia nigra pathology in Alzheimer's disease. J Histochem Cytochem 50:99-106

107. Schoch KM, DeVos SL, Miller RL, Chun SJ, Norrbom M, Wozniak DF, Dawson HN, Bennett CF, Rigo F, Miller TM (2016) Increased 4R-Tau Induces Pathological Changes in a Human-Tau Mouse Model. Neuron 90:941-947

108. Simic G, Babic Leko M, Wray S, Harrington CR, Delalle I, Jovanov-Milosevic N, Bazadona D, Buee L, de Silva R, Di Giovanni G, Wischik CM, Hof PR (2016) Monoaminergic neuropathology in Alzheimer's disease. Prog Neurobiol. doi: 10.1016/j.pneurobio.2016.04.001

109. Su B, Wang X, Nunomura A, Moreira Pl, Lee HG, Perry G, Smith MA, Zhu X (2008) Oxidative stress signaling in Alzheimer's disease. Curr Alzheimer Res 5:525-532

110. Theofilas P, Ehrenberg AJ, Dunlop S, Di Lorenzo Alho AT, Nguy A, Leite RE Rodriguez RD, Mejia MB, Suemoto CK, Ferretti-Rebustini RE, Polichiso L, Nascimento CF, Seeley WW, Nitrini R, Pasqualucci CA, Jacob Filho W, Rueb U, Neuhaus J, Heinsen H, Grinberg LT (2016) Locus coeruleus volume and cell population changes during Alzheimer's disease progression: A stereological study in human postmortem brains with potential implication for early-stage biomarker discovery. Alzheimers Dement. doi:10.1016/j.jalz. 2016.06.2362

111. Tiernan $C T$, Ginsberg SD, Guillozet-Bongaarts AL, Ward SM, He B, Kanaan NM, Mufson EJ, Binder LI, Counts SE (2016) Protein homeostasis gene dysregulation in pretangle bearing nucleus basalis neurons during the progression of Alzheimer's disease. Neurobiol Aging 42:80-90

112. Tomonaga M (1983) Neuropathology of the locus ceruleus: a semiquantitative study. J Neurol 230:231-240

113. Trumpower BL (1981) Function of the iron-sulfur protein of the cytochrome b-c1 segment in electron-transfer and energy-conserving reactions of the mitochondrial respiratory chain. Biochim Biophys Acta 639:129-155

114. Tymanskyj SR, Scales TM, Gordon-Weeks PR (2012) MAP1B enhances microtubule assembly rates and axon extension rates in developing neurons. Mol Cell Neurosci 49:110-119

115. Unnerstall JR, Kopajtic TA, Kuhar MJ (1984) Distribution of alpha 2 agonist binding sites in the rat and human central nervous system: analysis of some functional, anatomic correlates of the pharmacologic effects of clonidine and related adrenergic agents. Brain Res 319:69-101

116. Wang J, Xiong S, Xie C, Markesbery WR, Lovell MA (2005) Increased oxidative damage in nuclear and mitochondrial DNA in Alzheimer's disease. J Neurochem 93:953-962

117. Weinshenker D (2008) Functional consequences of locus coeruleus degeneration in Alzheimer's disease. Curr Alzheimer Res 5:342-345

118. West MJ (1993) Regionally specific loss of neurons in the aging human hippocampus. Neurobiol Aging 14:287-293

119. Whitehouse PJ, Price DL, Clark AW, Coyle JT, DeLong MR (1981) Alzheime disease: evidence for selective loss of cholinergic neurons in the nucleus basalis. Ann Neurol 10:122-126

120. Wilson RS, Nag S, Boyle PA, Hizel LP, Yu L, Buchman AS, Schneider JA, Bennett DA (2013) Neural Reserve, Neuronal Density in the Locus Coeruleus, and Cognitive Decline. Neurology 80:1202-1208

121. Winblad B, Palmer K, Kivipelto M, Jelic V, Fratiglioni L, Wahlund LO, Nordberg A, Backman L, Albert M, Almkvist O, Arai H, Basun H, Blennow K, de Leon M, DeCarli C, Erkinjuntti T, Giacobini E, Graff C, Hardy J, Jack C, Jorm A, Ritchie K, van Duijn C, Visser P, Petersen RC (2004) Mild cognitive impairment-beyond controversies, towards a consensus: report of the International Working Group on Mild Cognitive Impairment. J Intern Med 256:240-246

122. Yaffe K, Petersen RC, Lindquist K, Kramer J, Miller B (2006) Subtype of mild cognitive impairment and progression to dementia and death. Dement Geriatr Cogn Disord 22:312-319

123. Yokota T, Mishra M, Akatsu H, Tani Y, Miyauchi T, Yamamoto T, Kosaka K, Nagai Y, Sawada T, Heese K (2006) Brain site-specific gene expression analysis in Alzheimer's disease patients. Eur J Clin Investig 36:820-830

124. Zarow C, Lyness SA, Mortimer JA, Chui HC (2003) Neuronal loss is greater in the locus coeruleus than nucleus basalis and substantia nigra in Alzheimer and Parkinson diseases. Arch Neurol 60:337-341

125. Zhu X, Perry G, Moreira PI, Aliev G, Cash AD, Hirai K, Smith MA (2006) Mitochondrial abnormalities and oxidative imbalance in Alzheimer disease. J Alzheimers Dis 9:147-153 